\title{
Frequency distribution of dapsone $N$-hydroxylase, a putative probe for P4503A4 activity, in a white population
}

\begin{abstract}
Phenotypic trait values in 166 healthy white subjects (age range, 18 to 88 years) were determined for dapsone $\mathrm{N}$-hydroxylation, dapsone $\mathrm{N}$-acetylation, debrisoquin 4-hydroxylation, and $S$-mephenytoin $4^{\prime}$ hydroxylation after single oral dose administration of the probe drugs dapsone $(100 \mathrm{mg})$, debrisoquin $(10 \mathrm{mg})$, and mephenytoin $(100 \mathrm{mg})$. No associations or evidence of cosegregation were found between the individual routes of metabolism. Dapsone $N$-hydroxylation exhibited a unimodal distribution, with marked (tenfold) intersubject variability, and aging was associated with reduced $N$-oxidation. However, the other measured routes of metabolism were age independent, but intersubject variability in all of the trait measurements increased with age. In subjects younger than 50 years, $S$-mephenytoin 4 -hydroxylation was modestly (34\%) less in men than in women. In contrast, dapsone $N$-acetylation, dapsone $\mathrm{N}$-hydroxylation, and debrisoquin 4-hydroxylation were not influenced by gender. Previous smoking habit and alcohol consumption were not associated with a difference in any of the four routes of metabolism. Accordingly, the measured phenotypic traits of drug oxidation and $N$-acetylation appear to be quite robust in regard to some common demographic variabilities present in population studies, with the exception of dapsone $\mathrm{N}$-hydroxylase, which is affected by aging. (Clin Pharmacol Ther 1994;55:492500.)
\end{abstract}

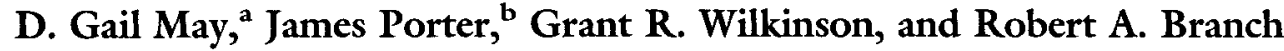 Nashville, Tenn.}

Dapsone is the drug of choice for leprosy ${ }^{1,2}$ and is recommended as an alternative treatment for chloroquine-resistant malaria. ${ }^{3}$ It is also used to treat certain chronic dermatologic disorders with an autoimmune component ${ }^{4-6}$ and to increase the healing rate of ulcers caused by brown recluse spider bites. ${ }^{7}$ Because dapsone has been recently advocated as therapy for treat-

From the Division of Clinical Pharmacology, Vanderbilt University School of Medicine.

Supported in part by grants GM 31304 and GM 46622 from the U.S. Public Health Service. Dr. May was a recipient of an award from the Burroughs Wellcome Fund.

Received for publication July 14, 1993; accepted Dec. 5, 1993.

Reprint requests: Robert A. Branch, MD, Center for Clinical Pharmacology, University of Pittsburgh Medical Center, 623 Scaife Hall, Pittsburgh, PA 15261.

${ }^{a}$ Current affiliation: Department of Clinical Pharmacology, Children's Hospital of Michigan, Wayne State University School of Medicine, Detroit, Mich.

${ }^{b}$ Current affiliation: Center for Clinical pharmacology, University of Pittsburgh Medical Center, Pittsburgh Medical Center, Pittsburgh, Pa.

Copyright $(1994$ Mosby-Year Book, Inc.

0009-9236/94/\$3.00+ $0 \quad \mathbf{1 3 / 1 / 5 3 4 5 5}$ ment of Kaposi's sarcoma ${ }^{8}$ and pneumonia caused by Pneumocystis carinii in patients with acquired immunodeficiency syndrome, ${ }^{9,10}$ clinical interest in the drug has increased. Adverse reactions to dapsone include hemolytic anemia and methemoglobinemia ${ }^{11}$ and have been attributed to the formation of oxidative metabolites. ${ }^{12-15}$ Increased knowledge about the extent of variability in the disposition of dapsone and the resulting consequences on efficacy and idiosyncratic adverse reactions may suggest strategies to broaden the therapeutic window of the drug.

Dapsone, an arylamine, is metabolized by both oxidative phase I and conjugative phase II processes. The best characterized metabolite of oxidation is dapsone hydroxylamine, whose formation has long been known to be mediated by cytochrome P450 (CYP). ${ }^{11}$ Recently we obtained evidence to suggest that an enzyme(s) of the CYP3A subfamily is responsible for more than $90 \%$ of $N$-hydroxylation in human liver microsomes. ${ }^{16}$ This same enzyme has also been reported to be responsible for the metabolism of numerous other drugs including nifedipine, ${ }^{17-18}$ cyclosporine, ${ }^{19-20}$ macrolide antibiotics, ${ }^{21}$ midazolam, ${ }^{22}$ triazo- 
lam, ${ }^{22}$ lidocaine, ${ }^{23}$ quinidine, ${ }^{24}$ and several steroids. ${ }^{25}$ Population studies with nifedipine initially suggested polymorphic distribution of a phenotypic trait considered to measure enzyme activity. ${ }^{26}$ However, more extensive studies using drug clearance were unable to confirm this possibility, and it is now generally accepted that a broad unimodal distribution of enzyme(s) involved in its metabolism is likely. ${ }^{27}$ This contrasts to certain other CYP enzymes that are known to exhibit genetic polymorphism. Two such polymorphisms, involving the oxidation of debrisoquin ${ }^{28}$ and $S$-mephenytoin, ${ }^{29}$ have been characterized. Each of these reactions is mediated by a different enzyme, CYP2D6 and CYP2C ${ }_{\text {MP }}$, respectively. ${ }^{30-31} \mathrm{~A}$ second enzyme involved in the disposition of dapsone is arylamine $N$-acetyltransferase, which also exhibits a genetically independent polymorphism in humans, and individuals can be classified into fast or slow acetylator phenotypes. 32,33

In this study, a phenotypic measurement approach was used to characterize a population of healthy individuals for their ability to $N$-hydroxylate dapsone. To determine possible associations between this pathway of oxidation and other routes of metabolism, these same individuals were also evaluated with regard to their ability to $N$-acetylate dapsone, 4-hydroxylate debrisoquin and 4 '-hydroxylate $S$-mephenytoin. In addition, several factors with known potential to modify drug-metabolizing activity, including age, gender, smoking and alcohol intake, were assessed for their possible association with intersubject variability in the measured metabolic activities.

\section{METHODS}

Subjects. Unrelated white subjects were recruited to include both genders equally and to encompass a wide age range. Subjects who were not taking any medications were permitted to participate in the study after a medical history was obtained and after physical examination and routine biochemical screening to exclude those with evidence of liver, kidney, or heart disease. Recent smoking habit and history of ethanol consumption was obtained before the study. Subjects provided written consent to the protocol, which had been approved by the Institutional Review Committee at Vanderbilt University School of Medicine.

Protocol. Each subject received dapsone $(100 \mathrm{mg}$ orally) and a venous blood sample was drawn 8 hours after drug administration; the harvested plasma was frozen at $-20^{\circ} \mathrm{C}$ until analyzed. Urine was collected from 0 to 8 hours into a container with ascorbic acid (1 gm) as a preservative and, after the total volume was measured, an aliquot was similarly frozen. On a separate occasion, each subject simultaneously received debrisoquin (10 $\mathrm{mg})$ and mephenytoin (100 $\mathrm{mg}$ ) orally. Urine was again collected from 0 to 8 hours, the volume was recorded, and an aliquot was frozen at $-20^{\circ} \mathrm{C}$ until analysis.

Sample analysis. Plasma and urinary dapsone, plasma monoacetyldapsone, and urinary dapsone hydroxylamine were measured by separate HPLC-based assays. ${ }^{34}$ Urinary debrisoquin and 4-hydroxydebrisoquin were measured as described previously ${ }^{28}$ but with use of mass spectrometric detection. The urinary enantiomeric ratio of $S$ - to $R$-mephenytoin was determined by chiral capillary gas chromatography. ${ }^{29}$

Phenotypic indexes. To assess dapsone $N$-hydroxylation, the 0- to 8-hour urinary dapsone recovery ratio $\left(R_{\mathrm{DDS}}\right)$ was obtained on the basis of the following equation $^{35}$ :

$$
\mathrm{RR}_{\mathrm{DDS}}=\frac{\mathrm{HDA}}{\mathrm{HDA}+\mathrm{DDS}}
$$

in which HDA and DDS are the excreted amounts of dapsone hydroxylamine and unchanged dapsone, respectively. The $N$-acetylation ratio was determined from the ratio of the plasma concentrations of dapsone and monoacetyldapsone measured 8 hours after drug administration, as previously described. ${ }^{36}$

The ability of each subject to hydroxylate debrisoquin was assessed by the debrisoquin recovery ratio $\left(\mathrm{RR}_{\mathrm{Db}}\right)$ as follows ${ }^{37}$ :

$$
\mathrm{RR}_{\mathrm{Db}}=\frac{\mathrm{OH}-\mathrm{Db}}{\mathrm{OH}-\overline{\mathrm{Db}}+\mathrm{Db}}
$$

in which $\mathrm{Db}$ and $\mathrm{OH}-\mathrm{Db}$ are the respective amounts of debrisoquin and its 4-hydroxy metabolite excreted in the 0 - to 8 -hour urine. $S$-Mephenytoin 4 '-hydroxylation was assessed by the $S / R$ enantiomeric ratio of mephenytoin in the 0 - to 8 -hour urine. ${ }^{29}$

Statistical analysis. Frequency distributions of the indexes of the four metabolic routes are presented graphically as normit plots, which are normal probability depictions of a cumulative distribution with the $y$-axis rescaled by application of the inverse normal transformation. ${ }^{38}$ Thus the data are presented in units of standard deviation about the median, which is represented as zero.

Multiple regression was used to evaluate correlations among metabolic routes. ${ }^{39}$ The relationships among drug-metabolizing activity and age, gender, smoking habits, and alcohol intake were assessed with use of multiple ANOVA with age as a covariate. Regression analysis was used to evaluate the relation- 


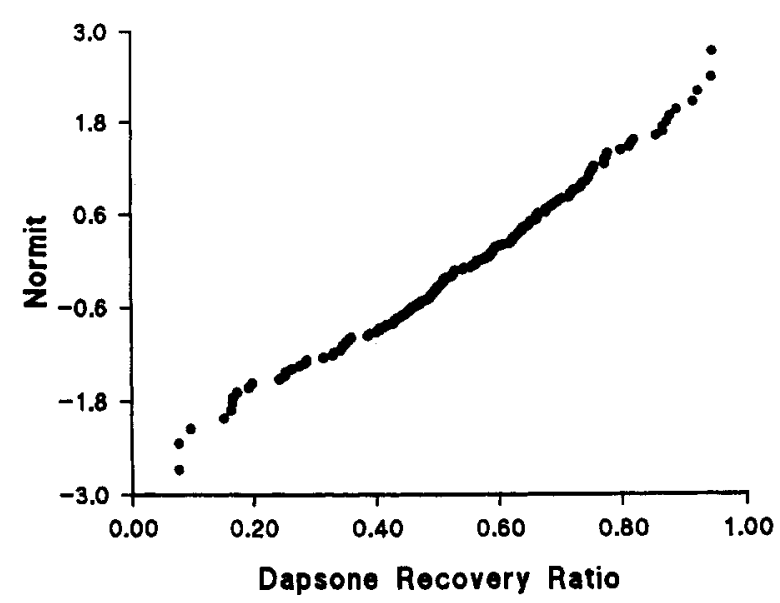

Fig. 1. Frequency distribution of the dapsone recovery ratio in 166 unrelated, healthy, drug-free white subjects.

ship between drug-metabolizing activity and age. A $p$ value $<0.05$ was accepted as statistically significant for all testing.

\section{RESULTS}

The study group consisted of 166 healthy white subjects, aged $56 \pm 17$ years (mean \pm SD), with an age range from 18 to 89 years. Fifty-four percent of the subjects were men, $36 \%$ smoked tobacco products, and $52 \%$ regularly consumed ethanol.

In this population, the frequency distribution of dapsone $N$-hydroxylation depicted as a normit plot appeared linear and continuous, suggesting a normal unimodal distribution (Fig. 1). Although no definite antimode was apparent in this distribution, there was a suggestion that three individuals with ratios less than 0.1 had reduced ability to hydroxylate dapsone compared with the remainder of the population. Repeated studies in two of these subjects confirmed such low activity. In a limited family study of five first-degree relatives of one of these probands, all had dapsone hydroxylation ratios close to the mean of the overall population. These family members were not included in the population analysis.

In contrast to the normit distribution of dapsone $N$-hydroxylation, the normit distribution of the debrisoquin recovery ratio was bimodal, with an apparent antimode of 0.02 (Fig. 2). Thirteen subjects (7.8\%) were classified as poor metabolizers and 153 subjects $(92.2 \%)$ were extensive metabolizers of debrisoquin. The normit distribution of the mephenytoin $S / R$ ratio was curvilinear (Fig. 3, upper panel), but log transformation converted this to an essentially linear distribution, except for a discrete subpopulation containing three poor metabolizers with $\log S / R$ ratios

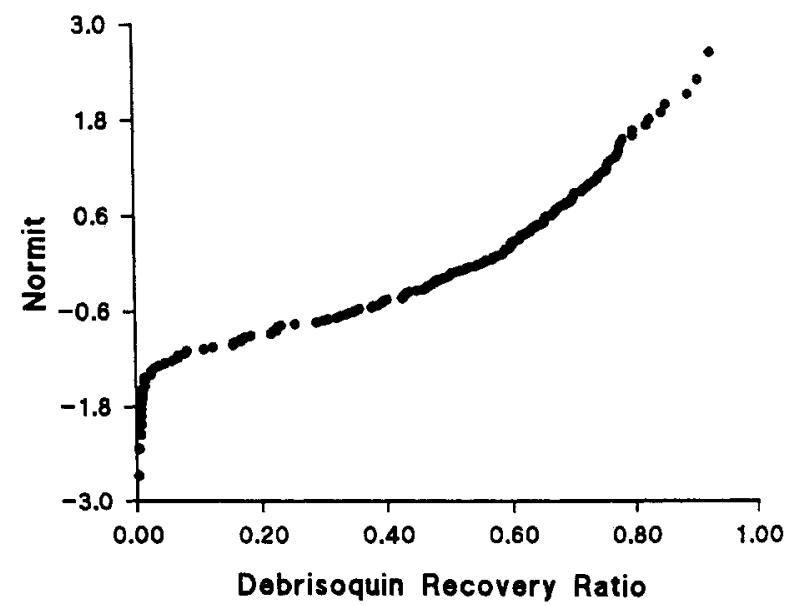

Fig. 2. Frequency distribution of the debrisoquin recovery ratio in 166 unrelated, healthy, drug-free white subjects.

greater than zero (Fig. 3, lower panel). Thus three subjects $(1.8 \%)$ were identified as poor metabolizers and 163 subjects $(98.2 \%)$ were classified as extensive metabolizers.

The frequency distribution of the dapsone acetylation ratio also appeared curvilinear on a normit plot, without any easily identified abrupt changes in slope (Fig. 4, upper panel). With use of previously established criteria ${ }^{36}$ for slow $(<0.3)$ and fast $(>0.35)$ phenotypes, 54 subjects $(32.5 \%)$ were found to be slow acetylators, whereas 100 subjects $(60 \%)$ were fast acetylators and $12(7.2 \%)$ were indeterminate. Interestingly, log transformation of the data yielded a trimodal distribution (Fig. 4, bottom panel), with a group of slow acetylators having a log acetylation ratio less than -0.7 (antilog 0.21 ), a group of intermediate acetylators having a $\log$ acetylation ratio between -0.7 and -0.21 (antilog 0.21 to 0.62 ), and a group of fast acetylators having a $\log$ acetylation ratio greater than -0.21 (antilog $>0.62$ ). With use of these criteria, 30 subjects $(18 \%)$ were slow acetylators, 82 subjects $(50 \%)$ were intermediate acetylators, and 54 subjects $(33 \%)$ were fast acetylators. Based on the Hardy-Weinberger equilibrium and assuming the slow acetylation trait to be autosomal recessive, ${ }^{33}$ the gene frequency of the slow acetylator trait was $42 \%$.

Multiple-regression analysis revealed no significant associations among the phenotypic indexes of the four routes of metabolism. Importantly, there was no evidence of cosegregation of poor metabolizers among the three oxidative routes of metabolism; that is, individuals defined as poor metabolizers for any single pathway of metabolism were extensive metabolizers for the other two routes (Table I). 

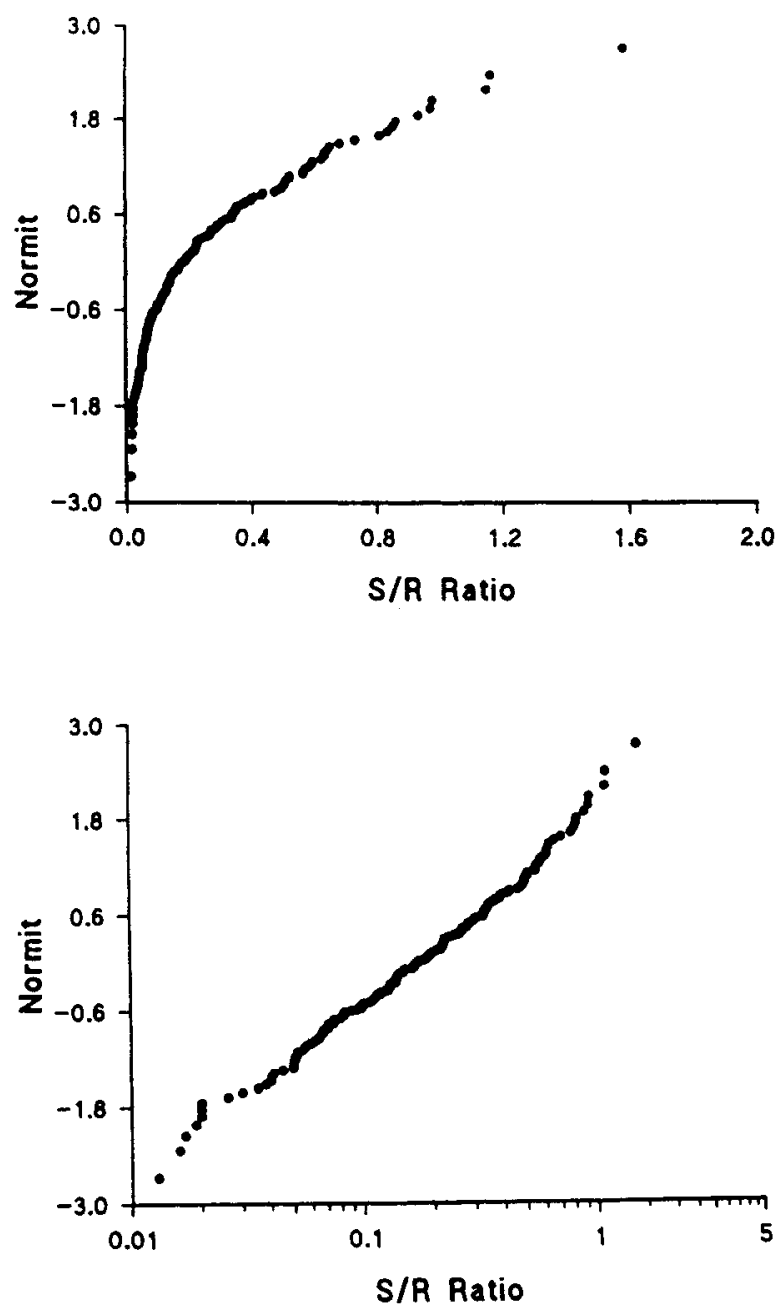

Fig. 3. Linear (upper panel) and log (lower panel) frequency distributions of the $S / R$-enantiomeric ratio of mephenytoin in 0- to 8-hour urine after oral administration to 166 unrelated, healthy, drug-free white subjects.

ANOVA incorporating gender, smoking habit, and history of ethanol consumption was performed, using age as a covariant in evaluating each of the measured phenotypic indexes. Neither smoking nor ethanol intake influenced the phenotypic indexes of any of the four studied routes of metabolism. Age contributed significantly to dapsone $N$-hydroxylation (ANOVA; $p<0.001$ ); with increasing age, the dapsone recovery ratio declined $\left(r^{2}=0.19 ; p<0.001\right)$ and variance increased (Fig. 5, upper left panel). Dapsone $N$-acetylation, debrisoquin 4-hydroxylation, and mephenytoin 4 '-hydroxylation were age-independent but also exhibited increasing variability with increasing age (Fig. 5; $F$ test; $p<0.01$ ).

In an attempt to evaluate possible gender differences according to age, the population was substrati-
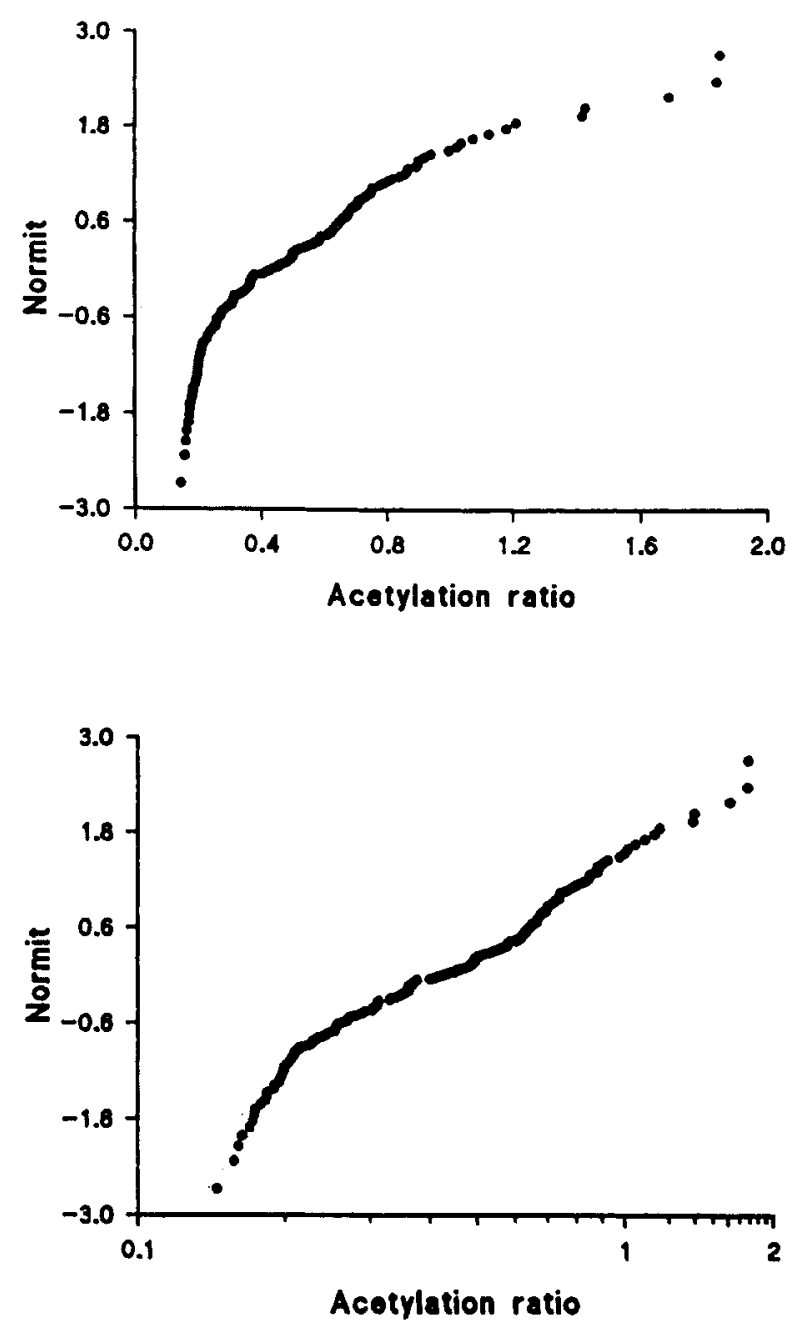

Fig. 4. Linear (upper panel) and $\log$ (lower panel) frequency distributions of the dapsone acetylation ratio 8 hours after dapsone administration to 166 unrelated, healthy, drugfree white subjects.

fied into two age groups using 50 years as an arbitrary cutoff. Gender did not influence either dapsone $\mathrm{N}$-hydroxylation or $\mathrm{N}$-acetylation, or debrisoquin 4-hydroxylation. By contrast, after the poor metabolizers were excluded, $S$-mephenytoin metabolism was influenced by gender to a very modest extent (Table II) in subjects under the age of 50 years. In this age group, women had a $34 \%$ lower $S / R$ enantiomeric ratio than men, indicating greater efficiency in their $4^{\prime}$ hydroxylation of $S$-mephenytoin.

\section{DISCUSSION}

This study clearly shows that dapsone $N$-hydroxylase activity exhibits a unimodal distribution in a population of healthy subjects. Dapsone $N$-hydroxyla- 
Table I. Comparison of phenotypic indexes of oxidative pathways in poor and extensive metabolizers for each of three routes of metabolism

\begin{tabular}{|c|c|c|c|}
\hline & \multicolumn{3}{|c|}{ Phenotypic index } \\
\hline & Debrisoquin recovery ratio & Mephenytoin $S / R$ ratio & Dapsone recovery ratio \\
\hline \multicolumn{4}{|l|}{ 4-Debrisoquin hydroxylation phenotype } \\
\hline Poor metabolizers $(n=13)$ & $0.01 \pm 0.004^{*}$ & $0.35 \pm 0.48$ & $0.67 \pm 0.14$ \\
\hline Extensive metabolizers $(n=153)$ & $0.52 \pm 0.22$ & $0.26 \pm 0.24$ & $0.55 \pm 0.19$ \\
\hline \multicolumn{4}{|l|}{$S$-Mephenytoin $4^{\prime}$ hydroxylation phenotype } \\
\hline Poor metabolizers $(n=3)$ & $0.35 \pm 0.32$ & $1.31 \pm 0.25^{*}$ & $0.56 \pm 0.09$ \\
\hline Extensive metabolizers $(n=163)$ & $0.48 \pm 0.25$ & $0.25 \pm 0.22$ & $0.56 \pm 0.19$ \\
\hline \multicolumn{4}{|l|}{ Dapsone $N$-hydroxylation ability } \\
\hline Low $(n=3)$ & $0.29 \pm 0.17$ & $0.47 \pm 0.25$ & $0.08 \pm 0.01^{*}$ \\
\hline High $(n=163)$ & $0.48 \pm 0.25$ & $0.27 \pm 0.26$ & $0.57 \pm 0.18$ \\
\hline
\end{tabular}

tion decreased with aging but was not influenced by gender, tobacco smoking, or ethanol consumption. Moreover, the ability to mediate this oxidation did not cosegregate with debrisoquin 4-hydroxylation, $S$ mephenytoin 4 '-hydroxylation, or dapsone $N$-acetylation. Therefore clear evidence exists that each of these drugs have the efficiency of their metabolism determined by different independently regulated drugmetabolizing enzyme systems.

The broad-based unimodal distribution of dapsone $N$-hydroxylation confirms extensive interindividual variation in the hydroxylation of this drug. ${ }^{35}$ Such interindividual variability undoubtedly reflects both genetic and environmental factors. Unfortunately, resolution of the relative contributions of alternative determinants, especially that of genetics, is difficult to discern in a population distribution study unless the effect is major and a sufficiently large subpopulation is affected. ${ }^{40}$ The current findings with $S$-mephenytoin exemplify this difficulty; even though the presence of a genetic polymorphism in $4^{\prime}$-hydroxylation is well established and is reflected by the 0 - to 8-hour urinary $S / R$ enantiomeric ratio, ${ }^{29,31}$ this phenomenon is not readily discernible from the frequency distribution data (Fig. 3) because of the low frequency of the poor metabolizer phenotype. By contrast, the greater proportion of poor metabolizers of debrisoquin within the population allows ready definition of two phenotypes (Fig. 2), although the reason for a lower antimode value in this study compared with an earlier report ${ }^{37}$ is unknown. On the other hand, pedigree studies, especially in family members of probands located at the extremes of the population distribution, have considerable power in identifying a genetically determined trait. For example, an increased familial incidence of impaired oxidation was found in the relatives of poor metabolizer probands for the debrisoquin ${ }^{41}$ and mephenytoin $^{42}$ polymorphisms, where the traits were found to be inherited in an autosomal recessive fashion. In the present study, no immediate family members of two of the subjects with the lowest rates of dapsone $N$-hydroxylation were available for study. However, five first-degree relatives of the third individual with a dapsone recovery ratio less than 0.1 were studied. In all cases, the phenotypic trait values were close to the mean of the larger population study. Accordingly, there is no evidence at the present time to support the notion of genetic polymorphism of dapsone $N$-hydroxylase.

We have previously shown that CYP3A4 is the major contributing enzyme to dapsone $N$-hydroxylation in human liver microsomes. ${ }^{16}$ We have suggested that this enzyme is likely to be a major contributor to in vivo metabolism in humans; however, the relative contribution of different enzyme systems to this specific metabolic pathway is currently unknown. The overall efficiency of this metabolic pathway can be measured in vivo by the fractional metabolic clearance to the $N$-hydroxylamine, and we have confirmed that the dapsone recovery ratio provides a phenotypic measure of this fractional clearance. ${ }^{35}$ Thus the broadbased unimodal distribution of dapsone $N$-hydroxylation is likely, as least in part, to represent CYP3A4 activity. It is of interest that nifedipine, another putative substrate for this enzyme, also exhibits a broad unimodal distribution of drug clearance with a sixfold to tenfold range of efficiency. ${ }^{27}$

Interestingly, aging was associated with a decreasing dapsone recovery ratio and increased intersubject variation (Fig. 5). These observations are consistent 

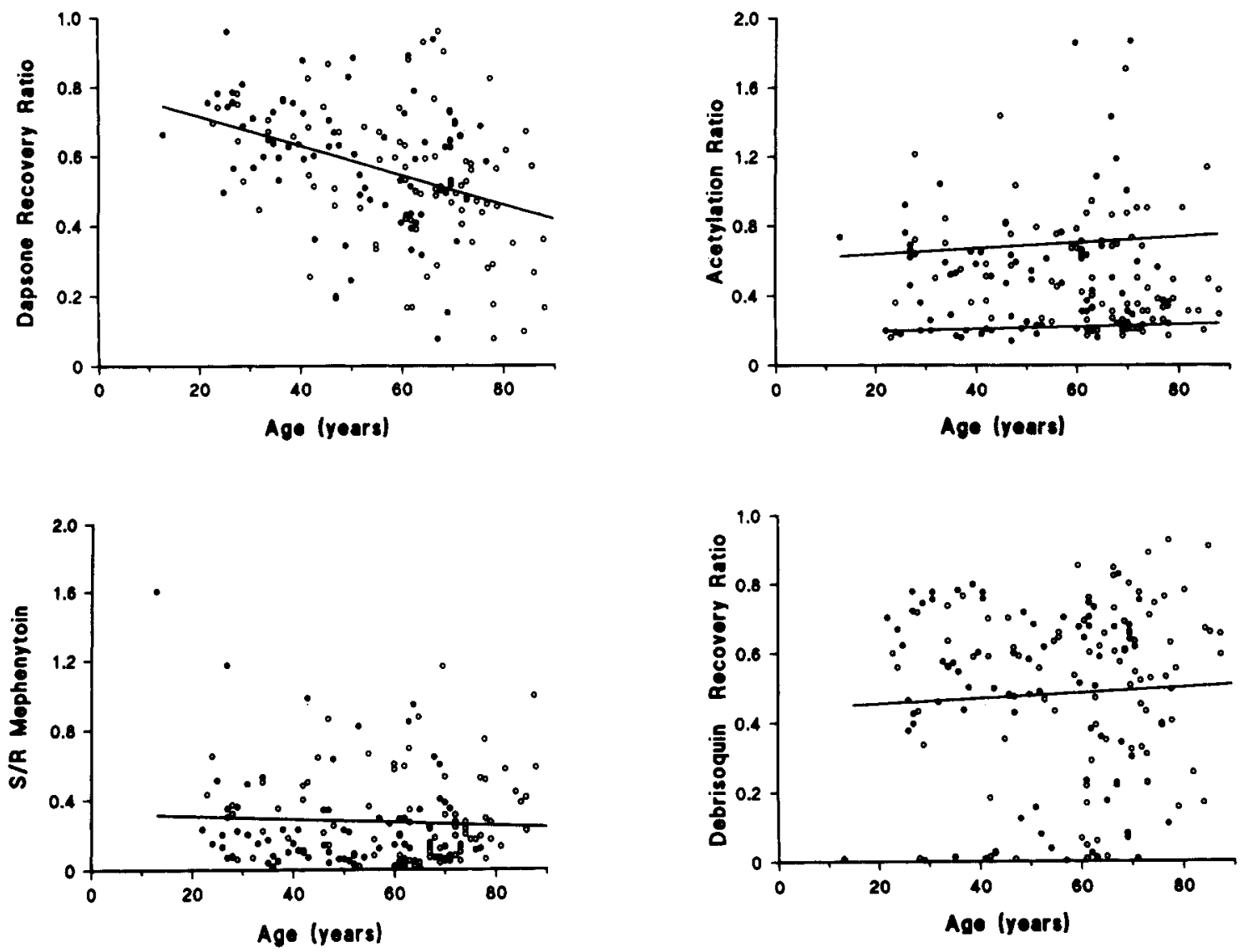

Fig. 5. Relationship of individual routes of drug metabolism to age in 166 unrelated, healthy, drug-free, male (solid circles) and female (open circles) white subjects. Regression lines indicate the nonstatistically significant relationships in debrisoquin extensive metabolizers, and mephenytoin extensive metabolizers, as well as slow acetylators (lower line), and fast acetylators (upper line) of dapsone, and the statistically significant relationship in all subjects for dapsone $N$-hydrox ylation.

with reports obtained with other putative substrates for CYP3A4. Pharmacokinetic studies in humans show reduced clearance of nifedipine ${ }^{43}$ and erythromycin ${ }^{44}$ in elderly subjects; however, microsomal activity of erythromycin and immunoblot quantification of CYP3A levels were not altered by age. ${ }^{45,46}$ The apparent discrepancy between observation could be attributed to reduced liver mass, with maintained specific activity for enzymes in aging. It is therefore possible that the clearance of all substrates mediated by CYP3A4 will be reduced in the elderly. The lack of age-related effects on the other studied phenotypic trait measurements of drug metabolism is consistent with previous reports. ${ }^{33,47,48}$

In contrast to the age-related change in dapsone $N$-hydroxylase activity, no gender-related differences were observed. This is consistent with previous re- ports with nifedipine ${ }^{27}$; however, the in vivo rates of $\mathrm{N}$-demethylation of erythromycin and $6 \beta$-hydroxycortisol formation, both putative routes mediated by CYP3A4, have been reported to be greater in women, ${ }^{47,49,50}$ and the in vitro rate of $N$-demethylation of erythromycin was greater in women. ${ }^{45}$ The reason for these different observations with substrates of a putatively common enzyme is not currently known and may reflect contributions of closely related isozymes with different gender distribution. Interestingly, a small but statistically significant difference in $S$-mephenytoin 4 '-hydroxylation was observed between men and women younger than 50 years of age. Several independent population studies of this genetic polymorphism have not previously noted such a gender-related difference. ${ }^{31}$ Moreover, the observed higher level of $\mathrm{P}^{4502 C_{\mathrm{MP}}}$ activity is contrary to the 
Table II. Drug-metabolizing indexes of several routes of metabolism comparing gender-related differences in subjects $<50$ years and $\geq 50$ years

\begin{tabular}{lll}
\hline & Age $<50$ yr & Age $\geq 50$ yr \\
\hline $\begin{array}{l}\text { Dapsone recovery ratio }(n=166) \\
\quad \text { Men }\end{array}$ & $0.64 \pm 0.147(22)$ & $0.50 \pm 0.19(68)^{*}$ \\
$\quad$ Women & $0.64 \pm 0.163(36)$ & $0.54 \pm 0.19(40)^{*}$ \\
Mephenytoin $S / R$ ratio $(n=164)$ & $0.32 \pm 0.22(24)$ & $0.24 \pm 0.21(66)$ \\
$\quad$ Men & $0.21 \pm 0.16(33) \dagger$ & $0.21 \pm 0.21(40)$ \\
$\quad$ Women & $0.53 \pm 0.20(18)$ & $0.53 \pm 0.22(32)$ \\
Debrisoquin recovery ratio $(n=153)$ & $0.56 \pm 0.85(66)$ & $0.53 \pm 0.24(37)$ \\
$\quad$ Men & $0.22 \pm 0.10(3)$ & $0.23 \pm 0.04(21)$ \\
$\quad$ Women & $0.20 \pm 0.04(16)$ & $0.22 \pm 0.03(14)$ \\
Slow acetylators $(n=54)$ & $0.68 \pm 0.3(19)$ & $0.66 \pm 0.3(39)$ \\
$\quad$ Men & $0.64 \pm 0.2 \quad(20)$ & $0.76 \pm 0.5(22)$ \\
$\quad$ Women & &
\end{tabular}

Data are mean values \pm SD.

Poor metabolizers of debrisoquin and mephenytoin were excluded from the analysis.

Sample size for each group is indicated in parentheses.

${ }^{*} p<0.01$ in comparison to $<50$ years.

$\dagger p<0.05$ in comparison between genders.

lower rate of propranolol side-chain oxidation in young women ${ }^{51}$ - a process that is mediated in part by this enzyme. ${ }^{52}$ Given the wide intersubject variability in mephenytoin $4^{\prime}$-hydroxylation within the extensive metabolizer phenotype, the observed gender-related difference may be a statistical artifact. A genderrelated difference has not been observed for CYP2D6 activity, ${ }^{45}$ and this factor has not been found to be a determinant of $\mathrm{N}$-acetylation metabolism. ${ }^{33}$

A history of alcohol or smoking was not associated with consistent changes in the phenotypic trait measurements of activity of any of the enzymes examined. However, a cross-sectional broad-based population approach, as used in this study, has limited ability to determine the influence of these factors on the regulation of these enzymes. These findings do not therefore exclude an effect of alcohol intake or smoking habit on the regulation of these isozymes.

Slow acetylation is caused by a decreased amount of polymorphic arylamine $N$-acetyltransferase $\mathrm{e}^{53,54}$ that is an autosomally recessive trait with Mendelian inheritance. ${ }^{33}$ Accordingly, three genotypes should be present in the population. However, most phenotyping procedures have been able to identify only two subpopulations and do not discriminate between the homozygous wild-type and heterozygous genotypes. ${ }^{33}$ Therefore the present finding of a trimodal pattern of distribution in the $\log$ dapsone acetylation ratio was somewhat surprising. A similar pattern in white subjects ${ }^{55}$ and Arabic subjects ${ }^{53}$ based on analysis of linearly distributed histograms has also been reported, with antimodes of 0.35 to 0.42 and 0.82 to 0.85 . The critical issue is whether the characterized phenotypes correspond to the actual genotypes, or whether the distribution pattern is fortuitous. For example, three phenotypes were defined in the distribution of the acetylation ratio in a Japanese population; however, the number of subjects in the fast and intermediate phenotypes were not consistent with the HardyWeinberg distribution. ${ }^{57}$ Moreover, recent studies that used molecular characterization of several $\mathrm{N}$-acetyltransferase alleles has indicated a high incidence of slow acetylator mutants in white populations, so that only about $8 \%$ of rapid acetylators are homozygous for the dominant wild-type gene. ${ }^{54}$ Such a distribution is inconsistent with the phenotypic populations characterized by the dapsone acetylation ratio (see Fig. 4 and Ward et al. ${ }^{52}$ ). Additional studies that compare phenotyping and genotyping information will be required to resolve this issue.

In summary, the phenotypic indexes of the measured polymorphically distributed drug-metabolizing enzyme activities appeared to be fairly robust with respect to common demographic variables present in population studies, that is, age, gender, tobacco smoking, and ingestion of ethanol. Thus these factors would be expected to have little if any effect on assignment of the correct phenotype. By contrast, dapsone $\mathrm{N}$ hydroxylation was found to be age dependent. It is likely that the observed variability in $N$-hydroxylation is a contributing factor to development of idiosyncratic adverse reactions after dapsone administration. 


\section{References}

1. Shepard CC. Leprosy today. N Engl J Med 1982;307: 1640-1.

2. Waters MFR. New approaches to chemotherapy for leprosy. Drugs 1983;26:465-7.

3. Powell RD, DeGowin RL, Bennet ER, McNamara JV, Carson PE. The antimalarial and hemolytic properties of 4-4'-diaminodiphenylsulfone (DDS). Int J Lepr 1967;35:590-4.

4. Swain AF, Ahmad RA, Rogers HJ, Leonard JN, Fry L. Pharmacokinetic observations on dapsone in dermatitis herpetiformis. Br J Dermatol 1983;108:91-8.

5. Kumano K, Tani M, Murata Y. Dapsone in the treatment of miliary lupus of the face. $\mathrm{Br} \mathrm{J}$ Dermatol 1983;109:57-62.

6. Grindulis KA, McConkey B. Rheumatoid arthritis: the effects of treatment with dapsone on hemoglobin. J Rheumatol 1984;11:776-8.

7. Rees RS, Altenbem DP, Lynch JP, King LE Jr. Brown recluse spider bites: a comparison of early surgical excision versus dapsone and delayed surgical excision. Ann Surg 1985;202:659-63.

8. Poulsen A, Hultberg B, Thomsen K, Wantzin GL. Regression of Kaposi's sarcoma in AIDS after treatment with dapsone. Lancet 1984;1:560.

9. Leoung GS, Mills J, Hopewell PC, Hughes W, Wofsy C. Dapsone-trimethoprim for Pneumocystis carinii pneumonia in the acquired immunodeficiency syndrome. Ann Intern Med 1986;105:45-8.

10. Lee BL, Medina I, Benowitz NL, Jacob P, Wofsy CB, Mills J. Dapsone, trimethoprim, and sulfamethoxazole plasma levels during treatment of Pneumocystis pneumonia in patients with the acquired immunodeficiency syndrome (AIDS). Ann Intern Med 1989;110:606-11.

11. Israili ZH, Cucinell SA, Vaught J, Davis E, Lesser, JM, Dayton PG. Studies of the metabolism of dapsone in man and experimental animals: formation of $\mathrm{N}$ hydroxy metabolites. J Pharmacol Exp Ther 1973; 187:138-51

12. Weisburger JH, Weisburger EK. Biochemical formation and pharmacological, toxicological and pathological properties of hydroxylamines and hydroxamic acids. Pharmacol Rev 1973;25:1-6.

13. Cucinell SA, Israili ZH, Dayton PG. Microsomal Noxidation of dapsone as a cause of methemoglobin formation in human red cells. Am J Trop Med Hyg 1972;21:322-31.

14. Glader BE, Conrad ME. Hemolysis by diphenylsulfones: comparative effects of DDS and hydroxylamineDDS. J Lab Clin Med 1973;80:267-72.

15. Grossman SJ, Jollow DJ. Role of dapsone hydroxylamine in dapsone-induced hemolytic anemia. J Pharmacol Exp Ther 1988;244:118-25.

16. Fleming CM, Branch RA, Wilkinson GR, Guengerich FP. Human liver microsomal $\mathrm{N}$-hydroxylation of dapsone by cytochrome P4503A4. Mol Pharmacol 1992; 41:975-80.

17. Guengerich FP, Martin MV, Beaune PH, Kremers P,
Wolff T, Waxman DJ. Characterization of rat and human liver microsomal cytochrome P-450 forms involved in nifedipine oxidation, a prototype for genetic polymorphism in oxidative drug metabolism. J Biol Chem 1986;261:5051-60.

18. Gonzalez FJ, Schmid BJ, Umeno M, et al. Human P450PCN1: sequence, chromosome localization, and direct evidence through cDNA expression that P450PCN1 is nifedipine oxidase. DNA 1988;7:79-86.

19. Kronbach T, Fisher V, Meyer UA. Cyclosporine metabolism in human liver: identification of a cytochrome P-450III gene family as the major cyclosporine-metabolizing enzyme explains interactions of cyclosporine with other drugs. Clin Pharmacol Ther 1988;43:630-5.

20. Combalbert J, Fabre I, Fabre G, et al. Metabolism of cyclosporin A; IV: purification and identification of the rifampicin-inducible human liver cytochrome P450 (cyclosporin A oxidase) as a product of P-450IIIA4 gene subfamily. Drug Metab Dispos 1989;17:197-207.

21. Ciaccio PJ, Halpert JR. Characterization of a phenobarbital-inducible dog liver cytochrome P450 structurally related to rat and human enzymes of the P450IIIA (steroid-inducible) gene subfamily. Arch Biochem Biophys 1989;271:284-99.

22. Kronbach T, Mathys D, Umeno M, Gonzalez FJ, Meyer UA. Oxidation of midazolam and triazolam by human liver cytochrome P4503A4. Mol Pharmacol 1989;36:89-96.

23. Bargetzi MJ, Aoyama T, Gonzalez FJ, Meyer UA. Lidocaine metabolism in human liver microsomes by cytochrome P-450IIIA4. Clin Pharmacol Ther 1989; 46:521-7.

24. Guengerich FP, Muller-Enoch D, Blair I. Oxidation of quinidine by human liver cytochrome P-450. Mol Pharmacol 1986;30:287-95.

25. Waxman DJ, Attisano C, Guengerich FP, Lapenson DP. Human liver microsomal steroid metabolism: identification of the major microsomal steroid hormone 6 beta-hydroxylase cytochrome P-450 enzyme. Arch Biochem Biophys 1988;263:424-36.

26. Kleinbloesem $\mathrm{CH}$, van Brummelen $\mathrm{P}$, Faber H, Danhof M, Vermeulen NPE, Breimer DD. Variability in nifedipine pharmacokinetics and dynamics: a new oxidation polymorphism in man. Biochem Pharmacol 1984; 33:3721-4.

27. Breimer DD, Schellens JHM, Soons PA. Nifedipine: variability in its kinetics and metabolism in man. Pharmacol Ther 1989;44:445-54.

28. Mahgoub A, Idle JR, Dring LG, Lancaster R, Smith RL. Polymorphic hydroxylation of debrisoquine in man. Lancet 1977;2:584-6.

29. Wedlund PJ, Aslanian WS, McAllister CB, Wilkinson GR, Branch RA. Mephenytoin hydroxylation deficiency in Caucasians: frequency of a new oxidative drug metabolism polymorphism. Clin Pharmacol Ther 1984; 36:773-80.

30. Meyer UA, Skoda RC, Zanger UM. The genetic polymorphism of debrisoquine/sparteine metabolism - mo- 
lecular mechanisms. Pharmacol Ther 1990;46:297-308.

31. Wilkinson GR, Guengerich FP, Branch RA. Genetic polymorphism of S-mephenytoin hydroxylation. Pharmacol Ther 1989;43:53-76.

32. Gelber R, Peters JH, Gordon R, Glazku AJ, Levy L. The polymorphic acetylation of dapsone in man. Cuis Pharmacol Ther 1971;13:225-38.

33. Evans, DAP. N-Acetyltransferase. Pharmacol Ther 1989;42:157-234.

34. May G, Porter JA, Uetrecht JP, Wilkinson GR, Branch RA. The contribution of $N$-hydroxylation and acetylation to dapsone pharmacokinetics in normal subjects. Clin Pharmacol Ther 1990;48:619-27.

35. May DG, Arns PA, Richards WO, et al. Influence of cirrhosis on the disposition of dapsone. Clin Pharmacol THER 1992;51:689-700.

36. Carr K, Oates JA, Nies AS, Woosley RL. Simultaneous analysis of dapsone and monoacetyldapsone employing high performance liquid chromatography: a rapid method for determination of acetylator phenotype. Br J Clin Pharmacol 1978;6:421-7.

37. Kaisary A, Smith P, Jacqz E, et al. Genetic predisposition to bladder cancer: ability to hydroxylate debrisoquine and mephenytoin as risk factors. Cancer Res 1987;47:5488-93.

38. Snecdor GW, Cochrane WG. Statistical methods. 7th ed. Ames, Iowa: Iowa State University Press, 1980.

39. Breslow WE, Day NE. Statistical methods in cancer research. IARC Sci Pub 1980;70:192-247.

40. Jackson PR, Tucker GT, Woods HF. Testing for bimodality in frequency distributions of data suggesting polymorphisms of drug metabolism-histograms and probit plots. Br J Clin Pharmacol 1989;28:647-53.

41. Evans DAP, Harmar D, Downham DY. The genetic control of sparteine and debrisoquine metabolism in man with new methods of analyzing bimodal distributions. J Med Genet 1983;20:321-9.

42. Ward SA, Goto F, Nakamunu K, Jacqz E, Wilkinson GR, Branch RA. S-Mephenytoin hydroxylase is inherited as an autosomal recessive trait in Japanese families. Clin Pharmacol Ther 1987;42:96-9.

43. Robertson DR, Waller DG, Renwick AG, George CF. Age-related changes in the pharmacokinetics and pharmacodynamics of nifedipine. $\mathrm{Br} \mathrm{J}$ Clin Pharmacol 1988;25:297-305.

44. Miglioli PA, Pivetta P, Strazzabosco M, Orlando R, Okolicsanyi L, Palatini P. Effect of age on single- and multiple-dose pharmacokinetics of erythromycin. Eur J Clin Pharmacol 1990;39:161-4.
45. Hunt Ch, Westerkam WR, Stave GM. Effect of age and gender on the activity of human hepatic CYP3A. Biochem Pharmacol 1992;44:275-83.

46. Schmucker DL, Woodhouse KW, Wang RK, et al. Effects of age and gender on in vitro properties of human liver microsomal monooxygenases. CuIN PHARMacol THER 1990;48:365-74.

47. Steiner E, Bertilsson L, Säwe J, Bertling I, Sjöqvist F. Polymorphic debrisoquine hydroxylation in 757 Swedish subjects. Clin Pharmacol Ther 1988;44:431-5.

48. Pollock BG, Pere] JM, Kirshner M, Altieri LP, Yeager AL, Reynolds III CF. S-Mephenytoin 4-hydroxylation in older Americans. Eur J Clin Pharmacol 1991;40:60911.

49. Watkins PB, Murray SA, Windelman LG, Heumann DM, Wrighton SA, Guzelian PS. Erythromycin breath test as an assay of glucocorticoid-inducible liver cytochromes P-450. J Clin Invest 1989;83:688-97.

50. Horsman Y, Desager JP, Harvengt C. Absence of CYP3A genetic polymorphism assessed by urinary excretion of $6 \beta$-hydroxycortisol in 102 healthy subjects on rifampicin. Pharmacol Toxicol 1992;71:258-61.

51. Walle T, Walle UK, Cowart TD, Conradi EC. Pathway-selective sex differences in the metabolic clearance of propranolol in human subjects. Clin Pharmacol Ther 1989;46:257-63.

52. Ward SA, Walle T, Walle UK, Wilkinson GR, Branch RA. Propranolol's metabolism is determined by both mephenytoin and debrisoquin hydroxylase activities. Clin Pharmacol Ther 1989;45:72-9.

53. Grant DM, Mörike K, Eichelbaum M, Meyer UA. Acetylation pharmacogenetics: the slow acetylator phenotype is caused by decreased or absent arylamine $\mathrm{N}$-acetyltransferase in human liver. J Clin Invest 1990;85:968-72.

54. Blum M, Demierre A, Grant DM, Heim M, Meyer UA. Molecular mechanism of slow acetylation of drugs and carcinogens in humans. Proc Natl Acad Sci USA 1991;88:5237-41

55. Clarke DWJ. Genetically determined variability in acetyltation and oxidation: therapeutic implications. Drugs 1985;29:342-75.

56. Irshaid YM, Al-Hadidi HF, Abuirjeie MA, Rawashdeh NM. $N$-Acetylation phenotyping using dapsone in a Jordanian population. Br J Clin Pharmacol 1991; 32:289-93.

57. Horai Y, Ishizaki T. $N$-Acetylation polymorphism of dapsone in a Japanese population. Br J Clin Pharmacol 1988;25:487-94. 